\title{
КОЛОННА С НИЗКИМ СОПРОТИВЛЕНИЕМ НА ОСНОВЕ ЭФФЕКТОВ ТЕРМИЧЕСКОЙ РЕКТИФИКАЦИИ
}

\author{
() Н.А. Войнов", Д.А. Земцов \\ Сибирский государственный технологический университет, пр. Мира, 82, \\ 660049 (Россия), e-mail: Voynov@siberianet.ru
}

\begin{abstract}
Целью исследования явилось использование термических эффектов при ректификации многокомпонентных смесей из растительного сырья.

В задачи исследования входило создание ректификационной колонны с низким гидравлическим сопротивлением и высокой разделяющей способностью ступеней на основе целенаправленного воздействия на процесс термическими эффектами, вызванными испарением и конденсацией.

Представлены результаты исследования процесса термической ректификации, полученные при укреплении смеси этанол - вода в колонне с 25 контактными ступенями, выполненными из горизонтально установленных пластин.

Установлено что эффективность разделения смеси на нижних ступенях исследуемой колонны при термической ректификации осуществляется преимущественно за счет эффекта, вызванного парциальной конденсацией, а на верхних ступенях - за счет испарения жидкости, размещенной на поверхности пластин.

Достигнуто низкое сопротивление колонны, не превышающее 40 Па, при сравнительно высокой эффективности разделения $0,4-0,7$.

Установлены параметры процесса, интенсифицирующие тепломассоперенос при термической ректификации.

Разработанную колонну вследствие ее высокой эффективности и низкого гидравлического сопротивления рекомендуется применять для проведения процессов ректификации под вакуумом, например для обезвоживания этанола.

Ключевые слова: ректификация, колонна, термические эффекты, эффективность, конденсация, испарение, дефлегматор, дистиллят.
\end{abstract}

\section{Введение}

Ректификация широко используется в лесохимической промышленности при получении продуктов потребления, восстановлении экстракционных растворов в процессах извлечения биологически активных веществ из растительного сырья, в технологии химической переработки древесины при производстве этанола, при переработке природных отходов газификацией.

Ректификации подлежат многокомпонентные смеси, как правило, азеотропные, имеющие близкую температуру кипения, что обусловливает использование для их разделения многоступенчатых ректификационных колонн.

В ряде случаев требуются мобильные малотоннажные установки для опытных производств (ректификация эфирного и талового масла, разделение растворителей в процессах выделения биополимера, экстракции растительного сырья) небольшой производительности, обладающие быстрой настройкой на новые смеси.

Одной из задач, стоящей при проведении процесса ректификации, является достижение высокой разделяющей способности колонны при низком гидравлическом сопротивлении, особенно при работе установок под вакуумом. В настоящее время повышение эффективности ступеней в основном достигается за счет турбулизации фаз, что приводит к росту сопротивления и уменьшению величины вакуума в колонне.

Для создания высокоэффективных колонн авторами настоящей статьи предлагается применять контактные ступени с низкими массообменными характеристиками, что обусловливает их малое сопротивление,

Войнов Николай Александрович - доктор технических наук, професcop, e-mail: voynov@siberianet.ru Земиов Денис Андреевич - аспирант, e-mail: denis_zemtsov.92@mail.ru а интенсификацию процесса ректификации осуществлять путем воздействия на процесс термических эффектов (испарения и конденсации). В этой связи

\footnotetext{
* Автор, с которым следует вести переписку.
} 
разработан [1-3] способ ректификации, заключающийся в создании флегмы по высоте колонны путем частичной конденсации паровой смеси на ступенях и дальнейшем воздействии на конденсат тепловым потоком поднимающегося пара.

Целью работы определены разработка и исследование колонны с низким гидравлическим сопротивлением на основе термической ректификации.

Схема экспериментальной установки представлена на рисунке 1. Колонна выполнена из царг диаметром 200 мм, снабжена 25 контактными ступенями высотой по 70 мм.

Контактная ступень (рис. 1, в) состоит из трех перфорированных пластин, изготовленных из медного листа толщиной 0,5 мм, края которых отбортованы на высоту 1 мм. Расстояние между пластинами выдерживалось равным 32 мм, а общая высота одной царги составила 70 мм. По оси колонны устанавливалась медная труба (дефлегматор) диаметром 26 мм, в полость которой подавалась охлаждающая вода при начальной температуре $10-70{ }^{\circ} \mathrm{C}$ согласно схемам, представленным на рисунке 2 . Тепловой поток паровой смеси, выходящей из куба, составил 3-15 кВт.

Согласно схеме потоков (рис. 1, б) поднимающиеся пары смеси по колонне частично конденсируются на наружной поверхности дефлегматора 14 с образованием флегмы, которая стекает по распределителям 15 на верхние пластины 11, где подогревается до температуры кипения с протеканием процессов испарения и конденсации. Количество флегмы на ступенях регулировалось расходом охлаждающей воды, подаваемой в полость трубы 14, согласно рисунку 2.

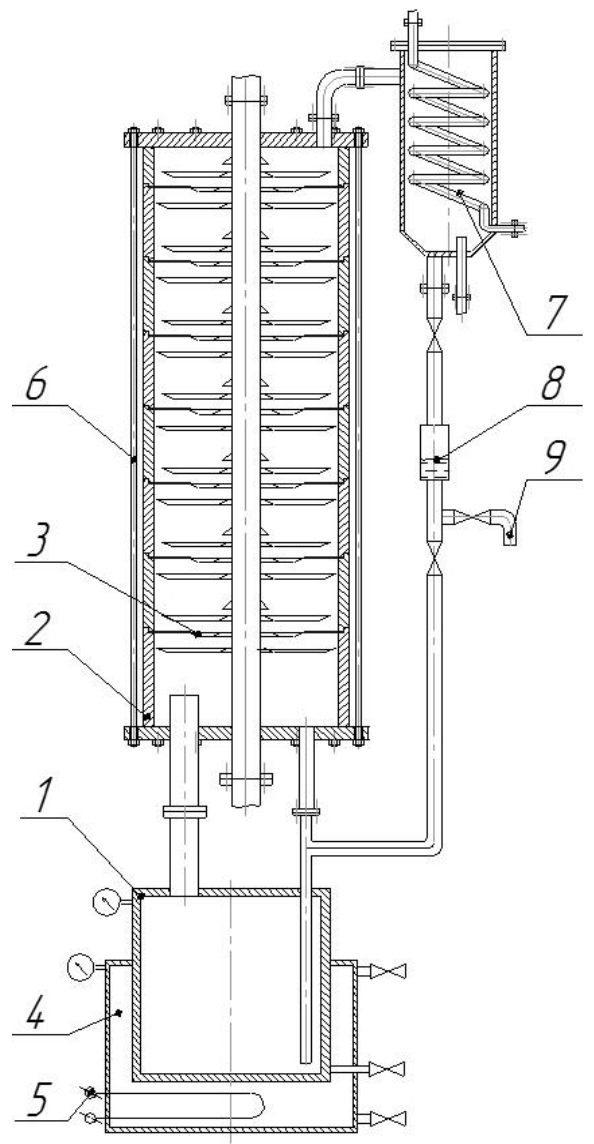

a)

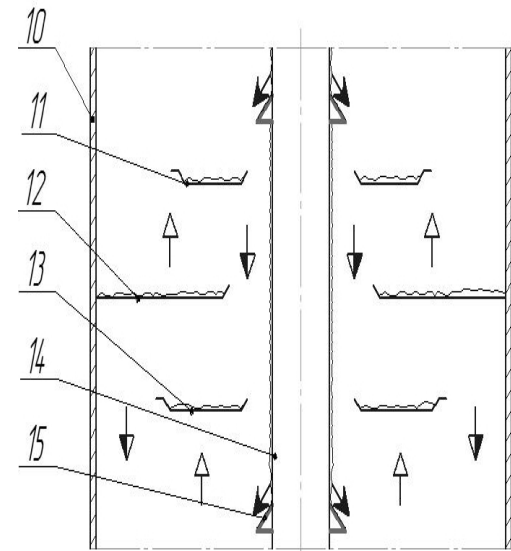

б)

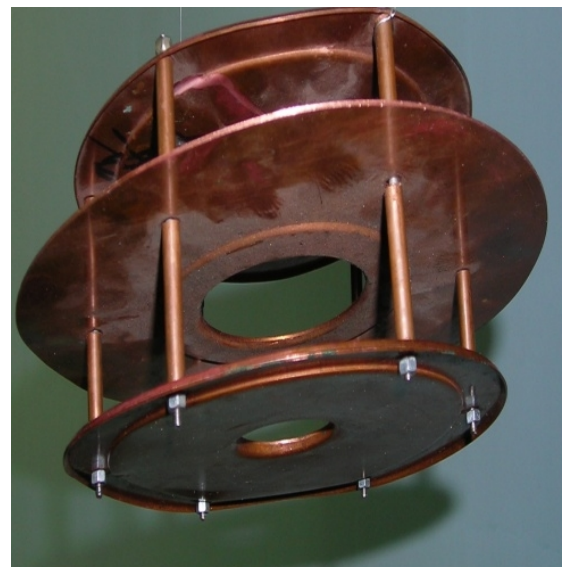

6)

Рис. 1. Схема колонны термической ректификации: 1 - куб; 2 - колонна; 3 - тарелка; 4 - рубашка; 5 - электронагреватель; 6 - шпилька; 7 - конденсатор; 8 - смотровое окно; 9 - пробоотборник; 10 - царга; 11 - верхняя пластина; 12 - средняя пластина; 13 - нижняя пластина; 14 - дефлегматор; 15 - распределитель конденсата; $\rightarrow$ - вода; $\rightarrow$-пар; $\rightarrow$ - рабочая смесь; $\rightarrow$-конденсат 
Исследовалась смесь этиловый спирт - вода с начальной концентрацией этанола в кубе 1-60\% масс. Состав смеси определялся при помощи рефрактометра марки LR-3. Расход воды, подаваемой в установку, измерялся ротаметрами типа РС-5. Показания температуры в жидкой и паровой фазах определялись термометрами сопротивления марки ТСМ-9418 при помощи вторичных приборов термодат 35 ЦО/ ГВС. Как установлено экспериментально, на показания термометра сопротивления при сравнительно низких расходах пара оказывает влияние скорость поднимающихся паров (рис. 3).

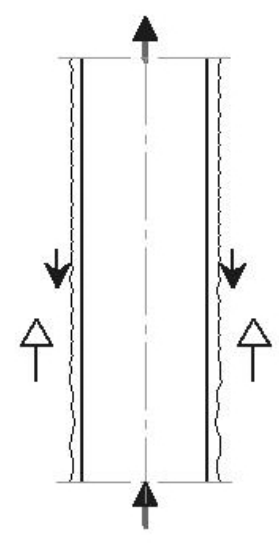

a)

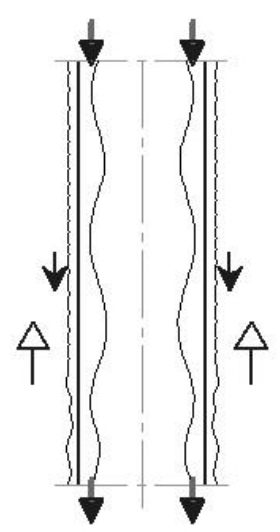

б)

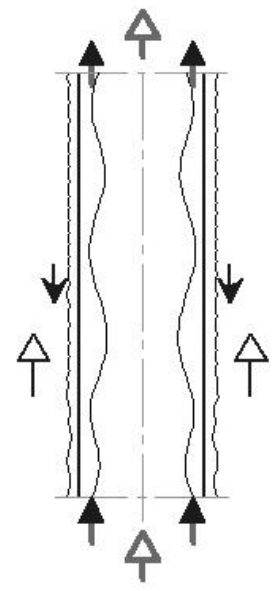

6)

Рис. 2. Схема подачи воды в дефлегматор: a) однофазный поток; б) гравитационное стекание пленки; в) восходящий прямоток (обозначение потоков см. на рис. 1)

Эффективность тарелки рассчитывалась по Мерфри:

$$
E_{y}=\frac{y_{\kappa}-y_{H}}{y^{*}-y_{H}},
$$

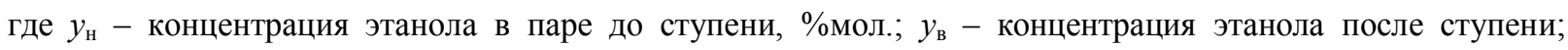
$y^{*}$ - равновесная концентрация.

Расходы пара и жидкости по колонне определялись исходя из материального и теплового балансов. Величина коэффициента теплоотдачи при определении флегмового числа вычислялась согласно зависимостям, представленным в монографии [5].

\section{Обсуждение результатов}

Как установлено, давление в кубе колонны во всем исследованном интервале тепловой нагрузки не превышало 40 Па, что свидетельствует о низком гидравлическом сопротивлении контактных ступеней. Суммарное количество жидкости в аппарате составило 2,5 кг.

При осуществлении процесса ректификации в условиях термической ректификации скорость поднимающихся паров по высоте колонны изменялась согласно данным, представленным на рисунке 4.

В зависимости от способа организации подачи охлаждающей воды в дефлегматор величина коэффициента теплопередачи составила от 500 до 10000 Вт/ $\left(\mathrm{M}^{2} \times \mathrm{K}\right)$, а тепловой поток конденсата на ступени $G_{\text {кон }}=100-900$ Вт.

Общая высота единиц переноса в исследуемой колонне составила 0,05 м, что на порядок превышает значения, полученные в колоннах со стекающей пленкой и насадочных [6].

На процесс укрепления смеси большое влияние оказывает температура конденсата. Как установлено (рис. 5), максимальная концентрация этанола в дистилляте достигнута при разности температуры пара и подаваемой воды в дефлегматор на верхней ступени колонны, равной $\Delta t=10-20^{\circ} \mathrm{C}$. При меньших значениях $\Delta t$ снижение величины единиц переноса обусловлено недостатком флегмы на ступени, а при больших их значениях происходит снижение интенсивности испарения конденсата на пластинах.

В этой связи были проведены измерения температуры конденсата на ступени, значения которой представлены на рисунке 6. 


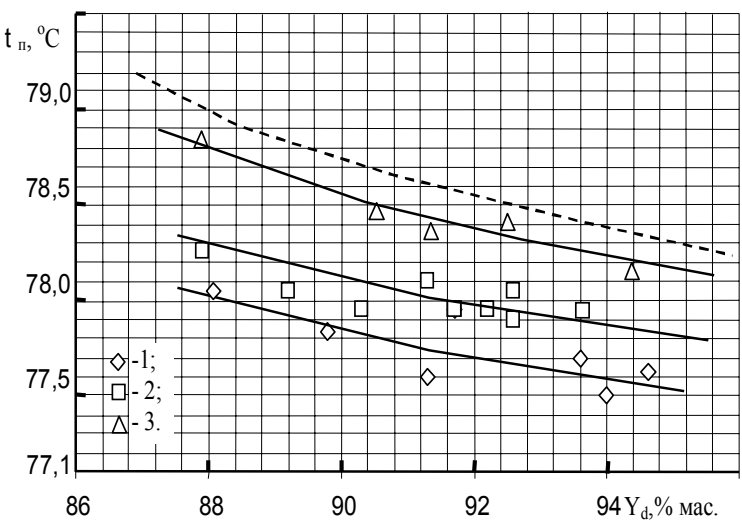

Рис. 3. Опытные показания температуры паров смеси на верхней ступени колонны термометром сопротивления в зависимости от концентрации этанола. Экспериментальные точки (1-3):

1 - скорость пара $u_{\Pi}=0,0025 \mathrm{M} / \mathrm{c} ; 2-0,015 \mathrm{M} / \mathrm{c}$; 3 - 0,035 м/с. Пунктирная линия согласно данным [4]

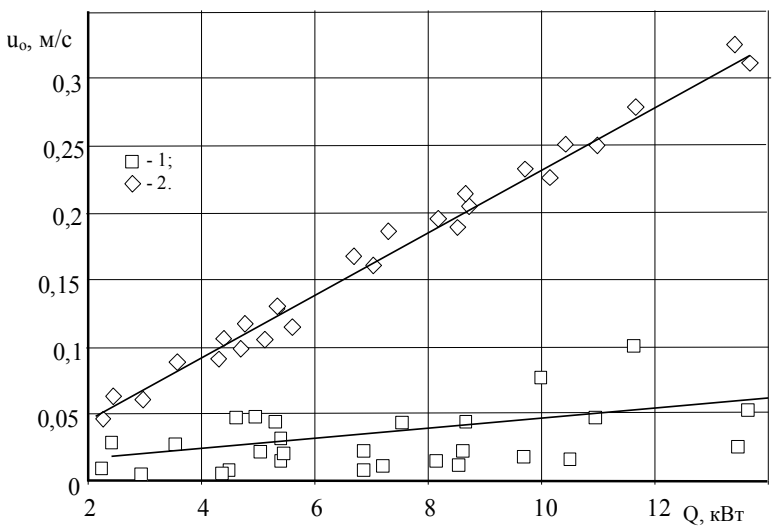

Рис. 4. Изменение среднерасходной скорости пара в колонне от тепловой нагрузки при флегмовом числе $R=0,5-15$. Экспериментальные точки (1-2): 1 - данные для верхней ступени; 2 - для нижней ступени

Установлено, что с увеличением расхода конденсата на ступени, а также с уменьшением температуры поступающей воды в дефлегматор и концентрации этанола в паре температура конденсата уменьшается.

Средняя эффективность контактной ступени при термической ректификации составляет $0,35-0,75$ (рис. 7) и с увеличением концентрации этанола в смеси возрастает.

Для выявления вклада парциальной конденсации на эффективность разделения проведены исследования в одиночной царге с дефлегматором 14 без пластин. Согласно данным (рис. 8) с уменьшением концентрации этанола в паре интенсивность укрепления за счет парциальной конденсации (из паровой смеси в конденсат больше уходит молекул воды, чем этанола) возрастает. При концентрации этанола в смеси более $70 \%$ масс. действие эффекта парциальной конденсации снижается.

В этой связи можно предположить, что эффективность разделения смеси на нижних ступенях исследуемой колонны при термической ректификации осуществляется преимущественно за счет эффекта парциальной конденсации, а на верхних ступенях - за счет испарения жидкости, размещенной на поверхности пластин. Таким образом, при эксплуатации установок подобного типа необходимо осуществлять подбор температуры теплоносителя на входе в дефлегматор с целью достижения оптимальной температуры конденсата на ступенях.

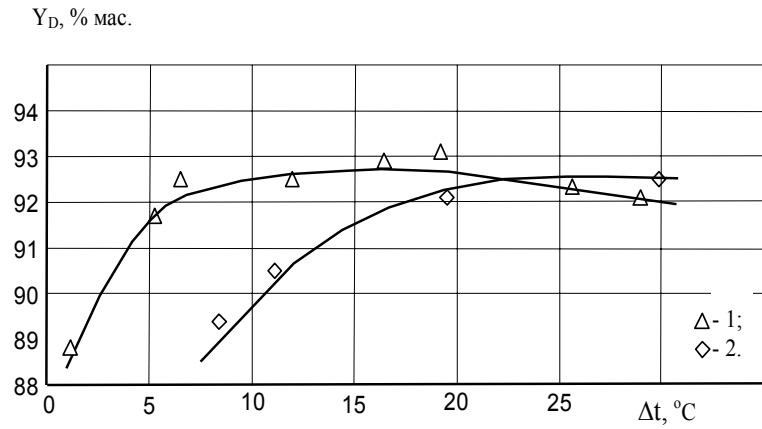

Рис. 5. Изменение концентрации этанола в паре на верхней ступени колонны в зависимости от температуры $\Delta t$ при начальной концентрации этанола в паре $60 \%$ масс. и тепловом потоке 14 кВт. Экспериментальные точки (1-2): 1 - при термической ректификации; 2 - при адиабатической ректификации

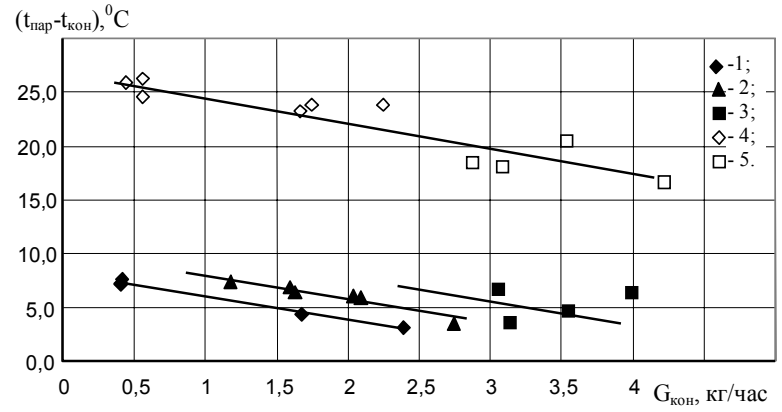

Рис. 6. Изменение температуры $t_{\text {пар }}-t_{\text {кон }}$ от расхода конденсата на ступени. Экспериментальные точки (1-3) получены при концентрации этанола 69-74\% масс. и (4-5) при 1-6\% масс. Точки: 1, 4- начальная температура воды в дефлегматоре $60{ }^{\circ} \mathrm{C} ; 2-45-36^{\circ} \mathrm{C} ; 3,5-5-7{ }^{\circ} \mathrm{C}$ 


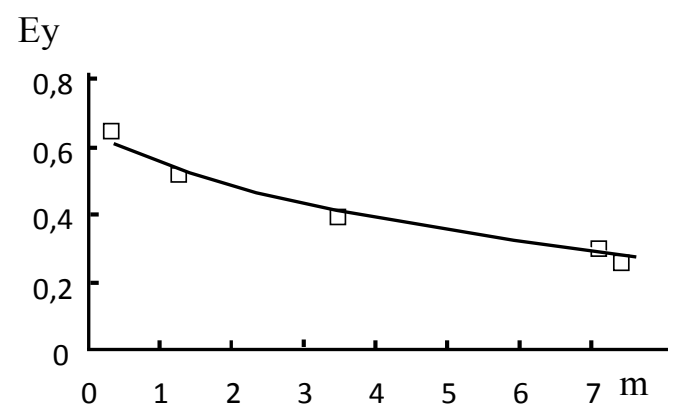

Рис. 7. Зависимость эффективности контактной ступени от тангенса угла наклона равновесной кривой при тепловом потоке куба 7 кВт

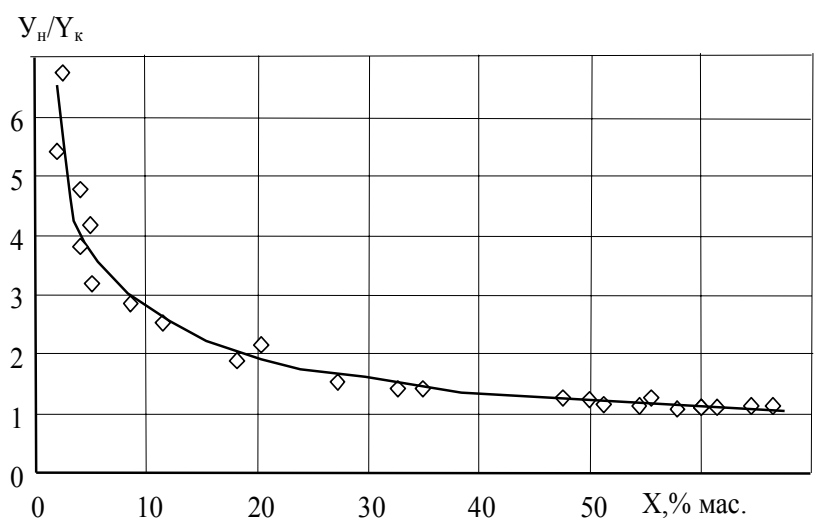

Рис. 8. Зависимость относительного содержания этанола в паре $y_{\text {н }} / y_{\text {к }}$ от концентрации этанола в конденсате при начальном содержании этанола в кубе $65 \%$ масс., где $Y_{\text {н }}$ и $V_{\text {к }}$ - соответственно концентрация этанола в паре на входе в царгу и на выходе

\section{Заключение}

Разработанная колонна вследствие ее высокой эффективности и низкого гидравлического сопротивления рекомендуется для проведения процессов ректификации под вакуумом, например для обезвоживания этанола.

\section{Список литературы}

1. Патент №2437698 (РФ). Способ ректификации / Н.А. Войнов, В.А. Паньков, А.Н. Войнов. 2011. 7 с.

2. Патент №2445996 (РФ). Ректификационная колонна / Н.А. Войнов, В.А. Паньков, А.Н. Войнов. 2012. 6 с.

3. Войнов А.Н., Жукова О.П., Паньков В.А., Войнов Н.А. Ректификация этилового спирта в колоннах со спирально-призматической насадкой // Техника и технология пищевых производств. 2012. Т. 4, №27. С. $95-99$.

4. Стабников Н.А. Справочник этиловый спирт. М., 1977. 56 с.

5. Войнов Н.А. Теплосъем при пленочном течении жидкости. Боргес, 2005. 123 с.

6. Олевский В.М., Ручинский В.Р., Кашников А.М., Чернышев В.И. Пленочная тепло- и массообменная аппаратура (Процессы и аппараты химической и нефтехимической технологии). М., 1988. 240 с.

Поступило в редакцию 7 июля 2015 г.

После переработки 19 ноября 2015 г. 


\section{FICATION \\ Voinov N.A.*, Zemtsov D.A. COLUMN WITH LOW RESISTANCE BASED ON THE EFFECT THERMAL RECTI- \\ Siberian State Technological University, pr. Mira, 82, 660049 (Russia), e-mail: Voynov@siberianet.ru}

The aim of the study was the use of thermal effects in the rectification of multicomponent mixtures of vegetable raw materials. The objectives of the study included the creation of a distillation column with a low flow resistance and high separating ability levels on the basis of deliberate action on the thermal effects caused by the process of evaporation and condensation. The results of investigation of thermal rectification obtained by strengthening ethanol-water mixture in a column with 25 stages pin made of horizontally fixed plates.It was found that the efficiency of separation of the mixture at the lower levels investigated by thermal distillation column is carried out mainly due to the effect caused by partial condensation, and on the upper levels, due to the evaporation of liquid placed on the surface of the plates.Column has reached a low resistance not exceeding $40 \mathrm{~Pa}$, at a relatively high separation efficiency $0,4-0,7$.The parameters of the process intensifies heat and mass transfer in thermal distillation.Developed column due to its high efficiency and low hydraulic resistance are recommended for carrying out the processes of rectification under vacuum, for example ethanol dehydration.

Keywords: distillation, column, thermal effects, efficiency, condensation, evaporation, reflux condenser, distillate.

\section{References}

1. Patent 2437698 (RU). 2011. (in Russ.).

2. Patent 2445996 (RU). 2012. (in Russ.).

3. Voinov A.N., Zhukova O.P., Pan'kov V.A., Voinov N.A. Tekhnika i tekhnologiia pishchevykh proizvodstv, 2012, vol. 4, no. 27, pp. 95-99. (in Russ.).

4. Stabnikov N.A. Spravochnik etilovyi spirt. [Directory of ethyl alcohol]. Moscow, 1977, 56 p. (in Russ.).

5. Voinov N.A. Teplos"em pri plenochnom techenii zhidkosti. [The output power at the film flow of liquid]. Borges, 2005, 123 p. (in Russ.).

6. Olevskii V.M., Ruchinskii V.R., Kashnikov A.M., Chernyshev V.I. Plenochnaia teplo- $i$ massoobmennaia apparatura (Protsessy $i$ apparaty khimicheskoi $i$ neftekhimicheskoi tekhnologii). [Film Heat and Mass Transfer equipment (Processes and devices of chemical and petrochemical technology)]. Moscow, 1988, 240 p. (in Russ.).

Received July 7, 2015

Revised November 19, 2015

\footnotetext{
* Corresponding author.
} 